\title{
Shoulder Joint Position Sense in Thoracic Outlet Syndrome
}

\author{
C. Sayaca ${ }^{1}$, F. Eyuboglu² ${ }^{2}$ M. Çalık ${ }^{2}$, H. Guney-Deniz ${ }^{3}$, T. Fırat ${ }^{3}$, D. Kaya ${ }^{1}$ \\ 1 Department of Physiotherapy and Rehabilitation, Faculty of Healty Science Physical Therapy and Rehabilitation, \\ Bursa Uludag University, Bursa, Turkey \\ 2 Department of Physiotherapy and Rehabilitation, Faculty of Healty Science Physical Therapy and Rehabilitation, \\ Uskudar University, Istanbul, Turkey \\ ${ }^{3}$ Faculty of Physical Therapy and Rehabilitation, Hacettepe University, Ankara, Turkey
}

\section{CORRESPONDING AUTHOR:}

\section{Cetin Sayaca}

Fizyoterapi ve Rehabilitasyon Bölümü

Sağlık Bilimleri Fakültesi Fizyoterapi ve

Rehabilitasyon

Özlüce Görükle Kampüsü 16059 Nilüfer/

Bursa, Turkey

E-mail: cetinsayaca@uludag.edu.tr

DOI:

10.32098/mltj.01.2021.18

LEVEL OF EVIDENCE: 3

\begin{abstract}
SUMMARY
Objective. The aim of the study was to analyze joint position sense (JPS), and muscle strength \& endurance in patients with Thoracic Outlet Syndrome (TOS).

Methods. Eight patients with unilateral TOS and eight healthy controls participated. Pain, symptom duration, JPS, and strength\&endurance were evaluated.

Results. There was a difference in Absolute Error (AE) of the abduction at $70^{\circ}(\mathrm{p}=$ $0.02)$. There were differences in $\mathrm{AE}$ at $40^{\circ}(\mathrm{p}=0.01)$ and $130^{\circ}(\mathrm{p}=0.04)$ abduction between the affected side of patients and the dominant side of the healthy group. Additionally, the pain was related to poor Relative Error at $90^{\circ}$ abduction and $\mathrm{AE}$ at $130^{\circ}$ flexion $(\mathrm{p}=0.01)$. There was no difference in strength and endurance of flexion $(p>0.05)$ and abduction ( $p>0.05)$ to compare the affected and unaffected side of the patients with TOS. There were differences strength of flexion (at $60^{\circ} / \mathrm{sec} ; \mathrm{p}=0.05$ ), strength of abduction (at $60^{\circ} / \mathrm{sec} ; \mathrm{p}=0.01$ ), and endurance of abduction (at $180^{\circ} / \mathrm{sec}$; $\mathrm{p}=0.05)$ to compare affected side of patients with TOS and healthy person.

Conclusions. This study indicated that JPS was decreased at $40^{\circ} \& 70^{\circ} \& 130^{\circ}$ abduction, strength in flexion and abduction was also decreased. Proprioceptive and strengthening exercises should be considered to implement in patients with TOS.
\end{abstract}

\section{KEY WORDS}

Joint position sense; muscle strength; thoracic outlet syndrome; proprioception; shoulder.

\section{INTRODUCTION}

Thoracic outlet syndrome (TOS) is defined as the compression of brachial plexus and/or subclavian vessels at the level of a scalene triangle, costoclavicular space or retropectoral space (1). Etiological factors of the TOS are congenital, postural disturbances, and trauma which involving the neck and shoulder (2). Symptoms of TOS may include muscle weakness, paresthesia, discolouration, swelling, numbness, and pain in the neck or arm, and atrophy of the upper limb muscles $(3,4)$. However, pain is the most common symptom and abnormal posture is a preparative reason for being other symptoms in TOS (5).

Compression on brachial plexus and/or vessels may cause muscle spasm that produce compressive stress on neck and shoulder regions. Cervical compressive stress may inhibit the proprioceptive muscular feedback system (6).
Additionally, prolonged exposure to stress can impair proprioception-related muscle function (7), which can further damage muscle spindles (8). Although neck and arm pain have been accepted as the major symptoms in patients with TOS, there is no study to investigate the limb proprioception level and relationship between pain and joint position sense in patients with TOS. Decreased active joint position sense (AJPS) acuity for patients with unspecified shoulder pain (9) and neck pain (10) was shown in the literature.

The aims of this study were to analyse shoulder proprioception level in patients with TOS and to investigate the relationship between pain, joint position sense, and muscle strength \& endurance, and to compare with healthy peers. We hypothesized that JPS at painful shoulder decreases in patients with TOS. 


\section{MATERIALS AND METHODS}

The participants were informed of the scope and procedures of the study. The present study protocol was reviewed and approved by the Institutional Review Board (Decision Number: 61351342/2019-54). All metod complies with ethical standards of Muscle, Ligaments and Tendons Journal as previously described (11).

This prospective case-control study had each subject serve as their own internal control, using the uninvolved side of the patients and the dominant side of the healthy controls for comparison. Eight women patients with TOS and eight sex-age matched healthy controls participated in the present study.

The inclusion criteria were: 1) had been diagnosed with neurogenic TOS; 2) the unilateral symptoms; 3) patients who were women; 4) ages between 18 to 35. Patients with endocrine diseases (such as peripheral neuropathy caused by diabetes) and vascular disease (peripheral artery), and/ or a recent history of trauma/surgery (upper extremity and neck) were excluded from the study.

The subject who had a full range of motion of the upper extremities without pain were included as healthy control. Participants who were smokers, had diabetes mellitus, with previous rotator cuff, upper limb, neck surgery, and thorax were excluded from the present study.

Before starting tests, all subjects participated in 5 minutes general body warm-up using a treadmill. General body warm-up was started at $3.5 \mathrm{mph}$ or $4.0 \mathrm{mph}$ and speed was increased 1.0 or $1.5 \mathrm{mph}$ every 30 seconds until the player has reached his desired speed. After the general body warm-up, the specific warm-up for extremity muscles was started. The specific warm-up consisted of 5 minutes of submaximal exercise for upper extremity on a Biodex System Pro3 (Biodex Corp., Shirley, NY, USA) at $120 \%$ sec. A 20 -second rest interval was given between warm-up and testing. Participants were familiarized with the tests in a practice session before proper data collection. The monitor was placed in such a way as to provide visual feedback to the participants. Standardized verbal instructions and encouragement were given.

Evaluations were made in the following order: joint position sense assessment, pain assessment, and strength \& endurance assessment.

\section{Pain Assessment}

Pain intensity was assessed using a $10 \mathrm{~cm}$ visual analogue scale (VAS) during rest.

\section{Muscle Strength Assessment}

The isokinetic concentric muscle peak torque of the shoulder muscles was determined bilaterally at $60 \%$ and $180^{\circ} / \mathrm{s}$ by a Biodex System Pro3 isokinetic dynamometer. The range of motion was determined individually by each subject. Muscle peak torque was evaluated at 0 to $180^{\circ}$ flexion for the shoulder. Three maximal repetitions at $60^{\circ} \% \mathrm{~s}$ and $180^{\circ} / \mathrm{s}$ were performed with 5 minutes rest between the tests.

The isokinetic test was performed in flexion/extension and abduction/adduction of the affected shoulder in comparison with the contralateral side, and the dominant side of the healthy with concentric contractions in all movements. The parameter tested was muscle peak torque as Newton-meters. All participant performed 5 repetitions in flexion/ extension and abduction/adduction directions at $60^{\circ} \mathrm{s}$ for strength, and 15 repetitions in flexion/extension and abduction/adduction directions at $180^{\circ} / \mathrm{s}$ for endurance. Shoulder of the patients with TOS was evaluated bilaterally. The dominant arm of the healthy person was determined, which was defined as the arm used for writing.

The participant was seated in a comfortable position with the seatback at an angle of $70^{\circ}$ relative to the seat. The mechanical axis of the dynamometer was aligned with the axis of movement of the shoulder. Maximal abduction/ adduction and flexion/extension of the shoulder was taken at a rate of $60^{\circ} \%$ and $180^{\circ} \%$ from $0^{\circ}$ to $180^{\circ}$ with the elbow in full extension, according to standardized protocol (12), and as performed in user manual of the Biodex System Pro3 (13).

\section{Joint Position Sense Assessment}

Proprioceptive status was assessed by joint position sense (JPS) using an active angle reproduction (AAR) technique with eyes closed (14). The actual angle achieved by the subject and the difference from the target angle was recorded from the onscreen goniometer. When patients felt they had reached the target angle they pressed the stop button and the angle was recorded; they were not permitted to correct the angle. This process was repeated six times for each target angle. The midrange angles $\left(40^{\circ}, 70^{\circ}, 90^{\circ}\right.$, and $130^{\circ}$ ) were selected to maximize sensory input from muscle proprioceptors.

For the JPS test of the shoulder flexion/extension, the shoulder was moved from $0^{\circ}$ extension starting position passively to each of the target angle of $40^{\circ}, 70^{\circ}, 90^{\circ}$, and $130^{\circ}$. Each participant performed repetitions of both the shoulders in the movement patterns of the extension through flexion. The arm was held there for $10 \mathrm{~s}$ for the subject to memorize the position and then returned to $0^{\circ}$ extension. After a pause of $5 \mathrm{~s}$, the arm was moved by active contraction at an angular velocity approximating $2 \%$ and stopped when the participant perceived the target angle had been reached. For the JPS test of the shoulder abduction/adduction, the shoulder was moved from $0^{\circ}$ adduction starting posi- 
tion passively to each of the target angles of $40^{\circ}, 70^{\circ}, 90^{\circ}$, and $130^{\circ}$. Each participant performed repetitions of both the shoulders in the movement patterns of the adduction through abduction. The same procedure, which was used for shoulder flexion/extension JPS, was repeated for the shoulder abduction/adduction JPS determination.

Absolute and relative errors were calculated (15). Absolute Error (AE) is defined as the absolute difference between the target angle and the perceived angle. The Relative Error (RE) represents the variability of the errors between trials and indicates the consistency of proprioceptive performance. AR and RE were calculated for each of the 6 trials for the 4 target angles for each limb of each subject.

\section{Statistical analysis}

All data were analyzed with the Statistical Package for the Social Sciences (SPSS) version 14.0. Nonparametric tests were used because of the numeric data distribution non normal. Mann-Whitney U test was used to investigate differences of muscle peak torque and JPS between the patients and controls groups. Wilcoxon test was used to investigate differences of muscle peak torque and JPS between affected and non-affected sides of patients. The relationship between the pain, muscle peak torque, and joint position sense was evaluated using Spearman's correlation coefficient using two-sided tests. A correlation coefficient range between 0.30 and 0.39 reflects the poor agreement, between 0.40 and 0.59 reflect the moderate agreement, between 0.60 and 0.69 reflect the good agreement, between 0.70 and 0.75 reflect very good and those $>0.75$ indicates high agreement. Statistical significance was set at $\mathrm{p} \leq 0.05$.

\section{RESULTS}

Demographic information (age, weight, height) of people who participated in the study and were shown in table I. The mean value of pain was $6.0 \pm 1.51 \mathrm{~cm}$ and the mean duration of the symptoms were $12.25 \pm 2.71$ months.

Muscle peak torque values of shoulder muscle flexion in $60 \%$ sec, abduction in $60 \% \mathrm{sec}$ and abduction in $180 \% \mathrm{sec}$ were lower on the affected side of patients with TOS when compare with dominant side of healthy person $(\mathrm{p}=0.05, \mathrm{p}$ $=0.01, \mathrm{p}=0.05$ respectively) (table II). Muscle peak torque values between affected and unaffected sides of the patients with TOS were similar ( $p>0.05)$ (table III).

There was no difference in all RE values between affected and unaffected sides of the patients $(\mathrm{p}>0.05)$ (table IV). There was a difference in AE of the shoulder abduction at $70^{\circ}(\mathrm{p}=0.02)$ while were no differences in all flexion degrees and $40^{\circ}, 90^{\circ}$, and $130^{\circ}$ abduction between affected and unaffected sides of the patients $(\mathrm{p}>0.05)$ (table V). $R E$ values were similar between the affected side of patients with TOS and dominant side of the healthy group $(\mathrm{p}>0.05)$ (table VI). There were differences in AE values at $40^{\circ}(\mathrm{p}=$ $0.01)$ and $130^{\circ}(\mathrm{p}=0.04)$ abduction while were no differ-

Table I. Demographic information of the patients and healthy control.

\begin{tabular}{llll}
\hline & $\begin{array}{l}\text { Age (years) } \\
\text { Mean } \pm \text { SD }\end{array}$ & $\begin{array}{l}\text { Weight }(\mathbf{k g}) \\
\text { Mean } \pm \text { SD }\end{array}$ & $\begin{array}{l}\text { Height }(\mathrm{cm}) \\
\text { Mean } \pm \text { SD }\end{array}$ \\
\hline Patients $(\mathrm{n}=8)$ & $24.75 \pm 6.69$ & $57.56 \pm 10.15$ & $166.00 \pm 7.71$ \\
\hline Healthy $(\mathrm{n}=8)$ & $24.75 \pm 6.69$ & $58.13 \pm 8.06$ & $167.25 \pm 6.96$ \\
\hline
\end{tabular}

SD: Standard Deviation.

Table II. Differences in the muscle peak torque of shoulder muscle between the affected side of patients with TOS and dominant side of the healthy person.

\begin{tabular}{|c|c|c|c|c|}
\hline \multirow[t]{2}{*}{ Muscle Peak Torque (Nm) } & $\begin{array}{l}\text { Affected Side of Patients } \\
\qquad(n=8)\end{array}$ & $\begin{array}{l}\text { Dominant Side of Healthy } \\
\qquad(\mathrm{n}=8)\end{array}$ & \multirow[t]{2}{*}{$\mathbf{Z}$} & \multirow[t]{2}{*}{$\mathbf{p}$} \\
\hline & Mean \pm SD & Mean \pm SD & & \\
\hline Flexion $\left(60^{\circ} / \mathrm{sec}\right)$ & $27.25 \pm 8.19$ & $34.62 \pm 4.14$ & -1.953 & 0.05 \\
\hline Flexion $\left(180^{\circ} / \mathrm{sec}\right)$ & $30.25 \pm 11.02$ & $35.25 \pm 8.56$ & -0.895 & 0.38 \\
\hline Extension $\left(60^{\circ} / \mathrm{sec}\right)$ & $43.37 \pm 11.07$ & $44.50 \pm 5.26$ & -0.421 & 0.72 \\
\hline Extension $\left(180^{\circ} / \mathrm{sec}\right)$ & $39.62 \pm 11.58$ & $44.62 \pm 2.38$ & -1.001 & 0.32 \\
\hline Abduction $\left(60^{\circ} / \mathrm{sec}\right)$ & $19.62 \pm 6.19$ & $31.25 \pm 7.44$ & -2.426 & 0.01 \\
\hline Abduction $\left(180^{\circ} / \mathrm{sec}\right)$ & $17.75 \pm 13.32$ & $30.00 \pm 4.66$ & -1.953 & 0.05 \\
\hline Adduction $\left(60^{\circ} / \mathrm{sec}\right)$ & $39.37 \pm 10.64$ & $42.12 \pm 6.62$ & -1.420 & 0.16 \\
\hline Adduction $\left(180^{\circ} / \mathrm{sec}\right)$ & $33.37 \pm 12.91$ & $37.12 \pm 6.31$ & -0.422 & 0.72 \\
\hline
\end{tabular}

Mann-Whitney U; SD: Standard Deviation; Statistical significant difference with $\mathrm{p}=0.05$. 
Table III. Differences in the muscle peak torque of shoulder muscle between the affected side and nonaffected side of patients with TOS.

\begin{tabular}{|c|c|c|c|c|}
\hline \multirow{2}{*}{ Muscle Peak Torque (Nm) } & $\begin{array}{l}\text { Affected Side of Patients } \\
\qquad(\mathrm{n}=8)\end{array}$ & $\begin{array}{l}\text { Nonaffected Side of Patients } \\
\qquad(\mathrm{n}=8)\end{array}$ & \multirow[t]{2}{*}{$\mathrm{Z}$} & \multirow[t]{2}{*}{$\mathbf{p}$} \\
\hline & Mean \pm SD & Mean \pm SD & & \\
\hline Flexion $\left(60^{\circ} / \mathrm{sec}\right)$ & $27.25 \pm 8.19$ & $24.50 \pm 6.52$ & -0.813 & 0.41 \\
\hline Flexion $\left(180^{\circ} / \mathrm{sec}\right)$ & $30.25 \pm 11.02$ & $27.25 \pm 13.64$ & -0.524 & 0.60 \\
\hline Extension $\left(60^{\circ} / \mathrm{sec}\right)$ & $43.37 \pm 11.07$ & $43.75 \pm 8.41$ & -0.315 & 0.75 \\
\hline Extension $\left(180^{\circ} / \mathrm{sec}\right)$ & $39.62 \pm 11.58$ & $37.75 \pm 11.18$ & -1.153 & 0.25 \\
\hline Abduction $\left(60^{\circ} / \mathrm{sec}\right)$ & $19.62 \pm 6.19$ & $23.75 \pm 11.03$ & -1.476 & 0.14 \\
\hline Abduction $\left(180^{\circ} / \mathrm{sec}\right)$ & $17.75 \pm 13.32$ & $18.00 \pm 14.76$ & -0.943 & 0.34 \\
\hline Adduction $\left(60^{\circ} / \mathrm{sec}\right)$ & $39.37 \pm 10.64$ & $37.38 \pm 3.46$ & 0.000 & 1.00 \\
\hline Adduction $\left(180^{\circ} / \mathrm{sec}\right)$ & $33.37 \pm 12.91$ & $30.00 \pm 8.67$ & -1.219 & 0.22 \\
\hline
\end{tabular}

Mann-Whitney U test; SD: Standard Deviation; Statistical significant difference with $\mathrm{p}=0.05$.

Table IV. Difference RE values in the shoulder joint position sense (JPS) between the affected side and non-affected side of patients with TOS.

\begin{tabular}{|c|c|c|c|c|}
\hline \multirow{2}{*}{$\begin{array}{l}\text { Target angles of JPS } \\
\text { test (Degree) }\end{array}$} & $\begin{array}{l}\text { Patients Affected Side } \\
\qquad(\mathrm{n}=8)\end{array}$ & $\begin{array}{l}\text { Patients Non- Affected Side } \\
(\mathrm{n}=8)\end{array}$ & \multirow[t]{2}{*}{$\mathbf{Z}$} & \multirow[t]{2}{*}{$p^{*}$} \\
\hline & Mean \pm SD & Mean \pm SD & & \\
\hline $40^{\circ}$ Flexion & $44.37 \pm 4.83$ & $46.25 \pm 2.71$ & -0.847 & 0.39 \\
\hline $70^{\circ}$ Flexion & $74.62 \pm 7.44$ & $64.50 \pm 16.17$ & -1.120 & 0.26 \\
\hline $90^{\circ}$ Flexion & $93.75 \pm 6.56$ & $84.25 \pm 30.93$ & -0.314 & 0.75 \\
\hline $130^{\circ}$ Flexion & $135.00 \pm 7.63$ & $136.37 \pm 5.60$ & -0.524 & 0.60 \\
\hline $40^{\circ}$ Abduction & $40.37 \pm 6.86$ & $43.37 \pm 5.60$ & -1.682 & 0.09 \\
\hline $70^{\circ}$ Abduction & $71.12 \pm 3.87$ & $71.50 \pm 5.70$ & -0.422 & 0.67 \\
\hline $90^{\circ}$ Abduction & $90.37 \pm 4.77$ & $93.00 \pm 5.85$ & -0.736 & 0.46 \\
\hline $130^{\circ}$ Abduction & $131.62 \pm 8.78$ & $129.72 \pm 8.32$ & -0.420 & 0.67 \\
\hline
\end{tabular}

Wilcoxon test; SD: Standard Deviation; Statistical significant difference with $\mathrm{p}=0.05$.

Table V. Difference AE values in the shoulder joint position sense (JPS) between the affected side and non-affected side of patients with TOS.

\begin{tabular}{|c|c|c|c|c|}
\hline \multirow{2}{*}{$\begin{array}{l}\text { Target angles of JPS } \\
\text { test (Degree) }\end{array}$} & $\begin{array}{l}\text { AE of Patients Affected Side } \\
\qquad(n=8)\end{array}$ & $\begin{array}{l}\text { AE of Patients Non- Affected Side } \\
\qquad(n=8)\end{array}$ & \multirow[t]{2}{*}{$\mathrm{Z}$} & \multirow{2}{*}{$\mathbf{p}^{*}$} \\
\hline & Mean \pm SD & Mean \pm SD & & \\
\hline $40^{\circ}$ Flexion & $4.87 \pm 4.25$ & $6.25 \pm 2.71$ & -0.736 & 0.45 \\
\hline $70^{\circ}$ Flexion & $6.12 \pm 6.08$ & $10.75 \pm 12.81$ & -0.841 & 0.40 \\
\hline $90^{\circ}$ Flexion & $3.75 \pm 6.56$ & $5.75 \pm 3.28$ & -0.943 & 0.35 \\
\hline $130^{\circ}$ Flexion & $6.87 \pm 5.11$ & $6.62 \pm 5.26$ & -0.281 & 0.78 \\
\hline $40^{\circ}$ Abduction & $5.62 \pm 3.33$ & $5.12 \pm 3.80$ & -0.315 & 0.75 \\
\hline $70^{\circ}$ Abduction & $2.87 \pm 2.64$ & $4.75 \pm 3.05$ & -2.226 & 0.02 \\
\hline $90^{\circ}$ Abduction & $3.62 \pm 2.82$ & $5.50 \pm 3.16$ & -1.084 & 0.46 \\
\hline $130^{\circ}$ Abduction & $6.72 \pm 4.21$ & $6.62 \pm 4.21$ & 0.000 & 1.00 \\
\hline
\end{tabular}

*Wilcoxon test; SD: Standard Deviation; Statistical significant difference with $\mathrm{p}=0.05$. 
ences other values $(p>0.05)$ between the affected side of patients with TOS and dominant side of the healthy group (table VII).

When the effect of pain level on JPS was analysed, we found that as the pain increased RE of JPS deteriorated at $90^{\circ}$ abduction and AE of JPS at $130^{\circ}$ flexion (respectively, $\mathrm{r}$ : $-0,876 ; \mathrm{p}=0.004$ and $\mathrm{r}:-0.805 ; \mathrm{p}=0.016)($ table VIII).

\section{DISCUSSION}

The findings of the present study showed that 1) there was decreased shoulder joint position sense at $40^{\circ} \& 70^{\circ} \&$ $130^{\circ}$ abduction; 2) there was decrease in shoulder muscles strength in flexion and abduction, in shoulder muscle endurance in abduction; 3 ) there was a relationship between higher pain intensity and decreased shoulder joint position sense at $90^{\circ}$ abduction in patients with TOS.

In the present study, the decreased abduction and flexion muscle strength were found in patients with TOS. In addition, a decrease in the endurance of the shoulder abduction was detected in patients with TOS. We believe that these losses in strength and endurance may be related to the pain levels of the patients. Similarly, Ozcakar et al. investigated shoulder flexor/extensor muscle strength, fatigue, and endurance in patients with TOS using isokinetic dynamometer (16). The authors did not find any differences in flexor/extensor muscles strength and endurance. Although they stated that pain intensity was evaluated using the

Table VI. Difference RE values in the shoulder joint position sense (JPS) between the affected side of patients with TOS and dominant side of the healthy person.

\begin{tabular}{lcccc}
\hline $\begin{array}{l}\text { Target angles of JPS } \\
\text { test (Degree) }\end{array}$ & $\begin{array}{c}\text { Patients Affected Side } \\
(\mathbf{n}=\mathbf{8})\end{array}$ & $\begin{array}{c}\text { Healthy Dominant Side } \\
(\mathbf{n}=\mathbf{8})\end{array}$ & $\mathbf{Z}$ & \multirow{2}{*}{$\mathbf{p}^{*}$} \\
\cline { 2 - 5 } & $\mathbf{M e a n} \pm \mathbf{S D}$ & Mean \pm SD & -1.697 & 0.10 \\
\hline $40^{\circ}$ Flexion & $44.37 \pm 4.83$ & $70.12 \pm 3.31$ & -0.476 & 0.64 \\
\hline $70^{\circ}$ Flexion & $74.62 \pm 7.44$ & $72.25 \pm 4.86$ & -0.848 & 0.44 \\
\hline $90^{\circ}$ Flexion & $93.75 \pm 6.56$ & $91.00 \pm 4.41$ & -1.422 & 0.16 \\
\hline $130^{\circ}$ Flexion & $135.00 \pm 7.63$ & $128.12 \pm 6.15$ & -0.317 & 0.79 \\
\hline $40^{\circ}$ Abduction & $40.37 \pm 6.86$ & $41.25 \pm 2.37$ & -1.642 & 0.10 \\
\hline $70^{\circ}$ Abduction & $71.12 \pm 3.87$ & $68.12 \pm 3.04$ & -0.745 & 0.50 \\
\hline $90^{\circ}$ Abduction & $90.37 \pm 4.77$ & $89.37 \pm 2.38$ & -0.848 & 0.44 \\
\hline $130^{\circ}$ Abduction & $131.62 \pm 8.78$ & $131.87 \pm 3.48$ & &
\end{tabular}

*Mann-Whitney U; SD: Standard Deviation; Statistical significant difference with $\mathrm{p}=0.05$.

Table VII. Difference AE values in the shoulder joint position sense (JPS) between the affected side of patients with TOS and dominant side of the healthy person.

\begin{tabular}{|c|c|c|c|c|}
\hline \multirow[t]{2}{*}{ Target angles of JPS test (Degree) } & $\begin{array}{l}\text { Patients Affected } \\
\text { Side }(\mathrm{n}=8)\end{array}$ & $\begin{array}{l}\text { Healthy Dominant } \\
\text { Side }(n=8)\end{array}$ & \multirow[t]{2}{*}{$\mathrm{Z}$} & \multirow[t]{2}{*}{$\mathrm{p}^{*}$} \\
\hline & Mean \pm SD & Mean \pm SD & & \\
\hline $40^{\circ}$ Flexion & $4.87 \pm 4.25$ & $2.62 \pm 1.76$ & -0.866 & 0.39 \\
\hline $70^{\circ}$ Flexion & $6.12 \pm 6.08$ & $4.50 \pm 2.50$ & -0.054 & 0.96 \\
\hline $90^{\circ}$ Flexion & $3.75 \pm 6.56$ & $1.00 \pm 4.40$ & -0.848 & 0.40 \\
\hline $130^{\circ}$ Flexion & $6.87 \pm 5.11$ & $2.87 \pm 2.58$ & -1.935 & 0.53 \\
\hline $40^{\circ}$ Abduction & $5.62 \pm 3.33$ & $2.00 \pm 1.69$ & -2.503 & 0.01 \\
\hline $70^{\circ}$ Abduction & $2.87 \pm 2.64$ & $2.87 \pm 1.95$ & -0.214 & 0.83 \\
\hline $90^{\circ}$ Abduction & $3.62 \pm 2.82$ & $2.12 \pm 0.99$ & -1.029 & 0.30 \\
\hline $130^{\circ}$ Abduction & $6.72 \pm 4.21$ & $2.75 \pm 2.31$ & -2.044 & 0.04 \\
\hline
\end{tabular}

*Mann-Whitney U; SD: Standard Deviation; Statistical significant difference with $\mathrm{p}=0.05$. 
Table VIII. Relationship between VAS and AE\&RE of JPS at a different angle of flexion and abduction in TOS.

\begin{tabular}{|c|c|c|c|}
\hline & Angle & $\mathbf{r}$ & $\mathrm{p}^{*}$ \\
\hline \multirow{4}{*}{ VAS \& Shoulder AE of JPS in Flexion } & $40^{\circ}$ & .447 & 0.26 \\
\hline & $70^{\circ}$ & .000 & 1.00 \\
\hline & $90^{\circ}$ & -.289 & 0.48 \\
\hline & $130^{\circ}$ & $-.805^{*}$ & 0.01 \\
\hline \multirow{4}{*}{ VAS \& Shoulder AE of JPS in Abduction } & $40^{\circ}$ & .247 & 0.55 \\
\hline & $70^{\circ}$ & -.363 & 0.37 \\
\hline & $90^{\circ}$ & -.043 & 0.91 \\
\hline & $130^{\circ}$ & .242 & 0.56 \\
\hline \multirow{4}{*}{ VAS \& Shoulder RE of JPS in Flexion } & $40^{\circ}$ & .447 & 0.26 \\
\hline & $70^{\circ}$ & .319 & 0.44 \\
\hline & $90^{\circ}$ & -.289 & 0.48 \\
\hline & $130^{\circ}$ & -.233 & 0.57 \\
\hline \multirow{4}{*}{ VAS \& Shoulder RE of JPS in Abduction } & $40^{\circ}$ & -.303 & 0.46 \\
\hline & $70^{\circ}$ & -.553 & 0.15 \\
\hline & $90^{\circ}$ & -.876 & 0.00 \\
\hline & $130^{\circ}$ & -.123 & 0.77 \\
\hline
\end{tabular}

*Spearman test; r: Correlation coefficient; Statistical significant difference with $\mathrm{p}=0.05$.

numeric pain scale, there was no data about pain intensity of the patients in their manuscript (16). If their patients declared lower pain intensity, it may be explained why muscle strength and endurance were not affected in their study. Our patients gave 6 points out of 10 (average) about their pain intensity. We thought that muscle strength and endurance may be overcome by middle or high-level pain intensity ( 5 points and over). Other difference is the result of muscle strength between the present study and Ozcakar et al.'s study may ensue from varied data collection method for the muscle strength. Ozcakar et al. collected muscle peak torque/body weight while we took only muscle peak torque of muscle strength data. Therefore a direct comparison of the present study with Ozcakar et al.'s study is difficult because there was no information about data of pain intensity in their study (16).

This was the first study to investigate shoulder joint position sense in patients with TOS. Target angles of $40^{\circ}, 70^{\circ}$, $90^{\circ}$, and $135^{\circ}$ in sagittal and frontal planes were used to determine the JPS. These target angles were selected for the reason that $90^{\circ}$ and $135^{\circ}$ target angles should simulate overhead activities such as combing hair, taking something from the cabinet, etc.; $40^{\circ}$ and $70^{\circ}$ target angles should simulate daily living activities such as wearing, feeding, washing, etc. There was a difference in $70^{\circ}$ abduction joint position sense using $\mathrm{AE}$ values while there were no differences in other abduction and flexion degrees joint position sense using $\mathrm{AE}$ and $\mathrm{RE}$ values between the affected and unaffected side of patients. Although there were no statistically differences in flexion joint position sense using RE values while there were differences in $40^{\circ}$ abduction and $130^{\circ}$ abduction joint position sense using $\mathrm{AE}$ values between the affected side of patients and dominant side of the healthy controls. Yang et al. described AE values for shoulder joint in the frontal plane (abduction/adduction movement) as $7.4^{\circ}\left( \pm 3.8^{\circ}\right)$ and in the sagittal plane (flexion/extension movement) as $4.6^{\circ}\left( \pm 2.4^{\circ}\right)(17)$. Absolute and relative errors were calculated to determine JPS (14). Yang et al. showed that shoulder joint position sense decreased in the mid-range of the shoulder and it's related to function in patients with chronic shoulder stiffness (18). Authors suggested that the coordination among scapula muscles' activation were important to consider in the rehabilitation.

There was a relationship between higher pain intensity and decreased shoulder joint position sense at $90^{\circ}$ abduction (using $\mathrm{RE}$ values) and $130^{\circ}$ flexion (using $\mathrm{AE}$ values) in patients with TOS. In abduction, late and insufficient upward rotation of the scapula was shown in patients with TOS compared to healthy controls scapula. Inadequate shoulder girdle muscle control and reduced upward rotation of the scapula may cause shoulder range of motion. Abduction usually provokes to pain, neurological or vascular symptoms motion in patients with TOS (3). We found a positive relationship between pain levels and shoulder joint position 
sense error at $90^{\circ}$ abduction while there was no relationship in other abduction target angles. It is well known that the range of painful arc in shoulder impingement syndrome is 60 to 120 degree (19). Thus, $90^{\circ}$ abduction is in the middle of painful arc and overhead activities start after $90^{\circ}$ abduction. We thought that there might be a painful arc or angle in patients with TOS in analogy to impingement syndrome. In the present study, we also found a negative relationship between pain intensity and $130^{\circ}$ shoulder flexion joint position sense using $\mathrm{AE}$ values. It means when pain increases patients find easily target angle during shoulder flexion. We did not find any knowledge (anatomical and biomechanical) why this target angle was easily found by patients with TOS. There is a flexor posture impairment in patients with TOS (5). Flexor posture disorder is expected in patients with TOS. Based on the findings of our study, it was thought that the patients with flexor posture disorder perceive the point, where they feel the pain in 130 degrees of flexion position, as the last motion limit of the shoulder and therefore they reach this degree easily.

The first limitation of the present study was we did not collect the scapular motion data. Skandalakis et al. showed that altered scapular position and drooped/depressed shoulder girdle has been consistently described in these patients. The authors mentioned that altered scapular position and/or glenohumeral depression may cause impaired shoulder joint position sense (20). Therefore, scapular motion analysis and the relationship between the motion differences with joint position sense in TOS patients would enlighten the JPS deficits in these population. Secondly, only muscle peak torque of the muscles was collected. Muscle amplitude or timing should be important for JPS and muscles strength. Hence, muscle amplitude and/ or timing may be evaluated using superficial electromyography. The third limitation was the blood vessels and condition of soft tissue circulation to the affected arm was not assessed with ultrasound. Povlsen et al. showed that circulation and muscle strength were negatively affected in TOS (4). Because of, decreased endoneurial blood flow and the rate of nerve injury correlates with loss of vascular supply (21), circulation may affect directly mechanoreceptors activities. Additionally, circulation is important to enhance physical performance (22). Impairment of the circulation and muscle strength should be caused impairment of the proprioception. Also, the functional level of the patients was not assessed in the present study. Although TOS is a pathology originating from the cervical region, its symptoms are seen in the upper extremity, especially in the shoulder. In the study, the proprioceptive sense of the cervical region was not evaluated. We think this is an important limitation of the present study. Studies are needed to evaluate the proprioception of the cervical region in patients with TOS. Studies are also needed to evaluate the proprioception of neurogenic and vascular TOS.

\section{CONCLUSIONS}

The present study indicated that shoulder joint position sense was decreased at $40^{\circ} \& 70^{\circ} \& 130^{\circ}$ abduction, shoulder muscles strength in flexion and abduction was also decreased. Additionally, there was a relationship between higher pain intensity and decreased shoulder joint position sense at $90^{\circ}$ abduction in patients with TOS. Therefore, the clinicians should be aware of the proprioceptive and muscle strength deficiencies in these individuals. It is also important to consider the relationship between pain and joint position sense in thoracic outlet syndrome. Proprioceptive and muscular strengthening exercises with the postural adjustment would be considered to implement in the daily therapeutic exercise programs in patients with TOS. It is suggested that future studies might evaluate joint position sense, muscle strength, scapular dysfunction, circulation dysfunction, timing \& amplitude of shoulder and neck muscles in the large number of patients with TOS.

\section{ACKNOWLEDGEMENTS}

The authors wish to acknowledge Firat Yertutanol for his generous support for English editing.

\section{FUNDINGS}

Authors declare that they have no sponsor in the study design, in the collection, analysis and interpretation of data, in writing of the manuscript, and in the decision to submit the manuscript for publication.

\section{ETHICS}

The authors confirm this study meets the guidelines of the Declaration of Helsinki and after local ethical approval all subjects provided written informed consent.

\section{CONFLICT OF INTERESTS}

The authors declare that they have no conflict of interests. 


\section{REFERENCES}

1. Liu JE, Tahmoush AJ, Roos DB, Schwartzman RJ. Shoulder-Arm Pain from Cervical Bands and Scalene Muscle Anomalies. J Neurol Sci 1995;128:175-180.

2. Sanders RJ, Hammond SL, Rao NM. Thoracic outlet syndrome: a review. Neurologist 2008;14(6):365-373.

3. Watson LA, Pizzari T, Balster S. Thoracic outlet syndrome part 2: conservative management of thoracic outlet. Man Ther 2010;15(4):305-314.

4. Povlsen B, Hansson T, Povlsen SD. Treatment for thoracic outlet syndrome. Cochrane Database Syst Rev 2014;(11):CD007218.

5. Mackinnon SE. Thoracic Outlet Syndrome. Ann Thorac Surg 1994:58:287-289.

6. Corodo P, Gurfinkel VS, Bevan L, Kerr GK. Proprioceptive consequences of tendon vibration during movement. J Neurophysiol 1995;74(4):1675-1688.

7. Jensen C, Finsen L, Sogaard K, Christensen H. Musculoskeletal symptoms and duration of computer and mouse use. Int J Ind Ergon 2002;30(4):265-275.

8. Brockett C, Warren N, Gregory JE, Morgan DL, Proske U. A comparison of the effects of concentric versus eccentric exercise on force and position sense at the humeral elbow joint. Brain Res 1997;771(2):251-258.

9. Fyhr C, Gustavsson L, Wassinger C, Sole G. The effects of shoulder injury on kinaesthesia: a systematic review and meta-analysis. Man Ther 2015;20(1):28-37.

10. Treleaven J, Jull G, Stering M. Dizziness and unsteadiness following whiplash injury: characteristics features and relationship with cervical joint position error. J Rehabil Med 2003;35(1):36-43.

11. Padulo J, Oliva F, Frizziero A, Maffulli N. Muscles, Ligaments and Tendons Journal - Basic principles and recommendations in clinical and field Science Research: 2016 Update. MLTJ 2016;6(1):1-5.
12. Dvir Z. Isokinetics: muscle testing, interpretation and clinical application. $2^{\text {nd }} \mathrm{ed}$. London: Churchill Livingstone, 2003.

13. h t t p : / / w w w. biodex. com/site s/default/ files/835000man_06159.pdf. Last access date: 18/11/2018.

14. Ager AL, Roy JS, Roos M, Belley AF, Cools A, Hébert LJ. Shoulder proprioception: How is it measured and is it reliable? A systematic review. J Hand Ther 2017:30(2):221-231.

15. Sajjadi E, Olyaei GR, Talebian S, Hadian M-R, Jalaie S. The effect of forward head posture on cervical joint position sense. J Paramed Sci 2014;5;27-31.

16. Ozcakar L, Inanıcı F, Kaymak B, Abalı G, Cetin A, Hascelik Z. Quantification of the weakness and fatigue in thoracic outlet syndrome with isokinetic measurements. Br J Sports Med 2005;39:178-181.

17. Yang JL, Chen S, Jan MH, Lin YF, Lin JJ. Proprioception assessment in subjects with idiopathic loss of shoulder range of motion: Joint position sense and a novel proprioceptive feedback index. J Orthop Res 2008;26(9):1218-1224.

18. Yang JL, Jan MH, Hung CJ, Yang PL, Lin JJ. Reduced scapular muscle control and impaired shoulder joint position sense in subjects with chronic shoulder stiffness. J Electromyogr Kinesiol 2010;20(2):206-211.

19. Cloke DJ, Watson H, Purdy S, Steen IN, Williams JR. A pilot randomized, controlled trial of treatment for painful arc of the shoulder. J Shoulder Elbow Surg 2008;17(1):17-21.

20. Skandalakis JE, Mirilas P. Benign anatomical mistakes: the thoracic outlet syndrome. Am Surg 2001;67(10):1007-1010.

21. Cameron NE, Eaton Se, Cotter MA, et al. Vascular factors and metabolic interactions in the pathogenesis of diabetic neuropathy. Diabetologia 2001;44:1973-1988.

22. Ekblom B, Huot R, Stein EM, and Thorstensson AT. Effect of changes in arterial oxygen content on circulation and physical performance. J Appl Physiol 1975;39(1):71-5. 